\title{
Modular Electrification
}

\section{Dear Reader,}

in future, drive systems without electrification will be found only in niche applications. That seems to be the fundamental consensus at the moment. But beyond that, opinions are divided. If the internal combustion engine, electric machine, transmission, battery and auxiliary components need to be considered as a complete unit in order to maximise performance and minimise $\mathrm{CO}_{2}$ emissions at an acceptable development cost and at an affordable price for the customer, there is no ideal, all-encompassing strategy.

Battery-powered vehicles do not yet have a sufficient driving range to enable them to be used as a main vehicle, and what is more they are much more expensive than their conventional counterparts. Plug-in technology is not (yet) cost-effective for most owners. When it comes to the question of how much electrification is necessary, 48- $\mathrm{V}$ technology certainly offers a promising approach, at least in the lower vehicle segments. In this case in particular, it is important to consider to what extent the additional expense of electrified auxiliary units will be financially viable. And the changes relating to energy and thermal management also raise many questions, especially concerning costs. This is perhaps not so relevant for luxury car buyers, but it is the lower segments that by far make up the lion's share of all vehicles sold in Germany and elsewhere. In these target groups, plug-in hybrids and fully electric vehicles will not be easy to sell, as their purchase price far exceeds that of cars with conventional internal combustion engines. So-called mild and full hybrids, coupled with the above-mentioned $48-\mathrm{V}$ concepts, promise more immediate suc- cess on the market. And that is what counts in the end if fleet emissions are to be quickly and sustainably reduced. But this will only work if end-of-life conventional vehicles are replaced as quickly as possible by new vehicles with an electrified powertrain.

The technology is available, and it can be installed and sold. But how can customers also be motivated to buy these new electric systems? That is clearly the key challenge for the near future. Only when wide-scale hybridisation is available for the price of a diesel engine will customers be prepared to accept this new powertrain technology. This calls for modular approaches towards electrification which, alongside the technical optimum, also offer an entry-level system as a "people's hybrid" at an attractive price.

Best regards,

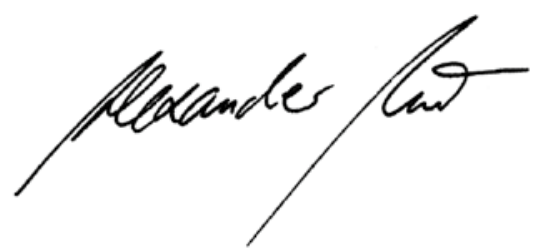

Dr. Alexander Heintzel, Editor in Chief Wiesbaden, 9 March 2015

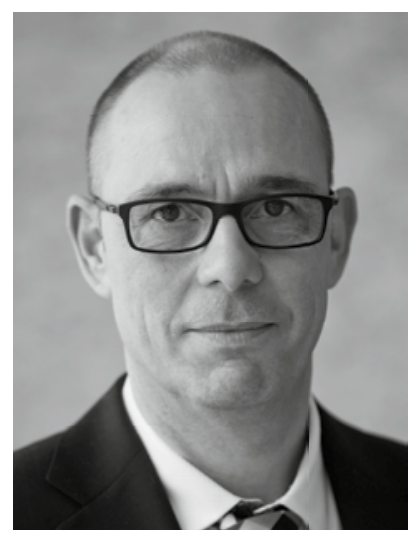

